\title{
New Association between Idiopathic Scoliosis and Luckenschadel Skull (Lacunar Skull)
}

\author{
Aysel Vehapoglu \\ Department of Pediatrics, Faculty of Medicine, Bezmialem Vakıf University, Istanbul, Turkey
}

\section{Highlights of the Study}

- Luckenschadel skull is considered a rare radiological finding associated with severe neurological abnormalities.

- We found that the lacunar skull is a very common benign condition that is not associated with any additional neurological pathology in children with idiopathic scoliosis. In addition, it does not disappear over time; in fact, it may become more obvious even up to the age of 16 years.

\section{Keywords}

Luckenschadel skull (lacunar skull) · Idiopathic scoliosis .

Chiari malformation

\section{Abstract}

Objective: Luckenschadel skull is a skull that is radiologically characterized by lacunae in the cranial vault. To date, although the association between neurological abnormalities and scoliosis is well recognized, no relationship between idiopathic scoliosis and a lacunar skull has been defined. We explored the incidence and time courses of lacunar skulls in patients with idiopathic scoliosis. Materials and Methods: Spinal X-rays of 3,170 children aged 6-16 years with idiopathic scoliosis evaluated from October 2010 to August 2020 were examined for the presence of an irregular inner calvarial table indicative of a Luckenschadel skull. A total of 1,760 $(55.5 \%)$ of the 3,170 images included the skull. We also explored the frequency of intraspinal abnormalities in children with lacunar skull images who underwent spinal magnetic resonance imaging. Results: The study population consisted of 1,760 children, 1,203 girls (68.4\%) and 557 (31.6\%) boys. A total of 268 (15.2\%) clearly evidenced lacunar skulls in their radiographs; 186 (69.4\%) girls (11.3 \pm 4.3 years) and 82 (30.6\%) boys ( $12.6 \pm 3.3$ years). Two of the 56 patients $(3.6 \%)$ who underwent spinal MRI had intraspinal abnormalities (isolated Chiari malformation-I). No additional neurological problems were detected in children with lacunar skulls. Conclusion: We conclude that the lacunar skull is very common in children with idiopathic scoliosis who lack any other neurological pathology. The lacunar skull does not disappear even in adolescence. Although previous publications have stated that lacunar skull disappears over time in radiographic images, we observed that it became more noticeable over time in children with scoliosis. @ 2021 The Author(s).

Published by S. Karger AG, Basel

\section{Introduction}

Luckenschadel skull, also known as the lacunar skull or "craniolacunae," is a dysplasia of the membranous skull vault and is readily apparent in plain radiography. It is a congenital defect, the physiopathology of which re-
(C) 2021 The Author(s)

Published by S. Karger AG, Basel

This is an Open Access article licensed under the Creative Commons Attribution-NonCommercial-4.0 International License (CC BY-NC) (http://www.karger.com/Services/OpenAccessLicense), applicable to the online version of the article only. Usage and distribution for commercial purposes requires written permission.
Correspondence to:

Aysel Vehapoglu, ayvahap@ hotmail.com 
mains poorly understood [1]. Its radiological features have been known since the early 1900s [2]. The first definition in the literature featured a skull deformity combined with spina bifida, the so-called Luckenschadel skull (gap skull) [3]. There is no information on the criteria for diagnosis of a lacunar skull (number and size) in the literature. Radiological data on the incidence of lacunar skull in the general population with or without scoliosis are lacking. The Luckenschadel skull has been considered an extremely rare mesenchymal dysplasia featuring calvarial ossification, characterized by groups of round, oval, or finger-shaped pits on the inner surface of the vault (the membranous part), separated by ridges of the bone [4]. It is usually evident in plain skull X-rays or computed tomography. Diagnostically, the bone exhibits thinning in some locations and is described as "copper-beaten" or "honeycombed" in direct skull radiography. The lacunae lie in the thickest parts of the frontal, parietal, and upper occipital bones, particularly the parietal bones. The defect is not caused by pressure from within (in contrast to the "copper-beaten" skull of patients with hydrocephalus), but rather by abnormal collagen production and ossification (skull vault ossification is membranous in nature). The inner table is more affected than the outer table; the gap is convex outward [5]. The lacunar skull has been commonly associated with neural tube defects (Chiari malformations [CMs] I-II, myelomeningocele, and craniosynostosis) [6,7]. It is not known whether otherwise normal children may have lacunar skulls.

Scoliosis is the most common orthopedic disease of children, but the cause is unknown. Scoliosis is defined as a lateral spinal curvature with a Cobb angle $\geq 10^{\circ}$ evident in a standing spinal radiograph $[8,9]$. Such abnormal curvature may reflect an underlying (congenital or developmental) osseous or neurological abnormality, or an environmental insult, but the etiology remains unclear. It is estimated that $0.47-5.2 \%$ of all children between the ages of 10 and 16 years exhibit some degree of abnormal spinal curvature, but only $2-3 \%$ of the general population [10]. Several types of scoliosis affect children and adolescents, and the most common type (80\%) is "idiopathic." The prevalence and severity of scoliosis are higher in girls than boys, with the female:male ratio increasing from 1.4:1 in patients with mild curves $\left(10-20^{\circ}\right)$ to $7.2: 1$ in patients with more severe curves $\left(>40^{\circ}\right)[11]$.

In recent years, the routine use of full spinal MRI for diagnosis and follow-up of patients with scoliosis has greatly increased the detection rate of neuro-axis abnormalities [12]. Dauser et al. [13] were the first to describe the association between the CM and scoliosis, and the lit- erature has grown over the past 3 decades. Intraspinal neural axis abnormalities such as an isolated CM, isolated syringomyelia, a CM combined with syringomyelia, and a tethered cord combined with diastematomyelia are common among patients with idiopathic scoliosis [1417]. The prevalence of such conditions has ranged from $11.1 \%$ to $26.0 \%$ in studies with small sample sizes [18]. A recent review shows that the prevalence of neural axis anomalies in children with idiopathic scoliosis is estimated to be around $11 \%$ [19]. Scoliosis commonly coexists with the neural axis anomalies, but no causal relationship has yet emerged.

To the best of our knowledge, no study has yet sought an association between a lacunar skull and scoliosis. All prior reports have linked lacunar skull to only severe neurological abnormalities. Thus, we explored the frequency of lacunar skull in children with idiopathic scoliosis by evaluating a large number of radiographic images.

\section{Materials and Methods}

The Bezmialem Vakıf University Local Research Ethics Committee approved this retrospective study and waived the requirement for written informed consent. We interrogated the database of Bezmialem Vakıf University Hospital (Istanbul) to identify lacunar skulls in children diagnosed with idiopathic scoliosis from October 2010 to August 2020. The medical records of 3,170 children aged 6-16 years with lateral spinal curvatures (Cobb angles) $\geq 10^{\circ}$ who underwent spinal X-ray were reviewed by the same observer in terms of the presence of an irregular inner calvarial table indicative of Luckenschadel skull. The study population consisted of 1,760 children with scoliosis: 1,203 girls (68.3\%) and 557 (31.6\%) boys. A total of $284(15.2 \%)$ clearly exhibited lacunar skulls in spinal radiographs. Of these, we studied 268 (15.2\%) children: 186 (69.4\%) girls and $82(30.6 \%)$ boys, with a female:male ratio of 2.26:1. The mean ages were $11.3 \pm 4.3$ years for girls and $12.6 \pm 3.3$ years for boys. In the present study, Luckenschadel skull was defined by groups of round or oval clearly evidenced finger-shaped pits on the inner surface of the vault, which vary in size, shape, and number, separated by ridges of the bone. We also evaluated the presence of intraspinal abnormalities in children with scoliosis for whom lacunar skull images were available and who underwent spinal MRI, by examining radiology reports.

\section{Subjects}

We enrolled a large group of subjects to determine the frequency of lacunar skull in children with scoliosis diagnosed via standing spinal radiography. Children with infantile scoliosis (age at onset $<3$ years) and with scoliosis that commenced at $<6$ years often exhibiting congenital neurological anomalies were excluded. We screened the records of idiopathic scoliosis patients aged $6-16$ years. Scoliosis was defined as a lateral spinal curvature (a Cobb angle) $\geq 10^{\circ}$. A total of 3,170 patients were initially included. A total of 1,760 (55.5\%) of the 3,170 images included the skull. We excluded 16 children with congenital neurological diseases or congenital scoliosis. 
Fig. 1. A 16-year-old girl with marked lacunar skull (multiple oval, round, and fingershaped pits on the inner surface of the vault, lie in frontal and parietal bones) and idiopathic scoliosis (left thoraco-lumbar scoliosis, curve of $26^{\circ}$ ) without any additional neurological pathology.
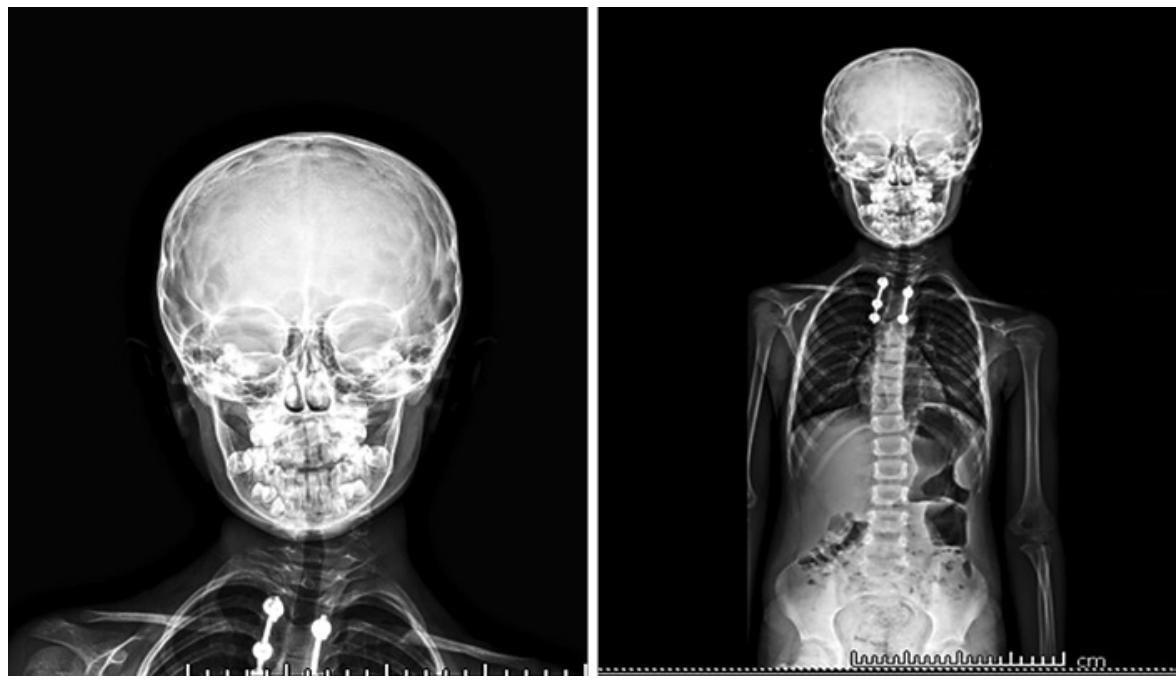

\section{Inclusion/Exclusion Criteria}

The inclusion criteria were children aged 6-16 years at diagnosis; scoliosis (Cobb angle $\geq 10^{\circ}$ in coronal images) as noted by radiologists; children with scoliosis whose skulls were imaged via anteroposterior, standing full-spine radiographs; and with initial normal neurological findings on medical records. The exclusion criteria were congenital scoliosis and any neuromuscular condition or syndrome. Chiari malformation type I (CM-I) was defined radiographically as a simple displacement of the cerebellar tonsils $5 \mathrm{~mm}$ or greater below the foramen magnum on MRI.

\section{Data Analyses}

All analyses were performed using the IBM Statistical Package for the Social Sciences for Windows (ver. 20.0; IBM Corp., Armonk, NY, USA). The results are presented as means \pm standard deviations for continuous variables and as frequencies with percentages for categorical variables. A $p$ value $<0.05$ was taken to indicate statistical significance.

\section{Results}

The study population consisted of 1,760 children, 1,203 girls (68.4\%) and 557 (31.6\%) boys. A total of 268 (15.2\%) clearly evidenced lacunar skulls in their spinal radiographs; $186(69.4 \%)$ girls (11.3 \pm 4.3 years) and 82 $(30.6 \%)$ boys (12.6 \pm 3.3 years). The lacunar image was mostly detected in the frontal and parietal bones. The female sex was significantly associated with scoliosis (68.3\%) and lacunar skull (69.4\%) in spinal radiographs (both $p<0.05$ ). Of the 268 children enrolled in the study, $151(56.3 \%)$ were adolescents aged 12 years and over. The study group consisted of $117(43.7 \%)$ children under 12 years of age. We noted that 142 (52.9\%) of 268 patients had been followed in our hospital for at least 3 years, and the lacunar head image persisted until the last radiographs. We observed that the lacunar head image of 29 (10.9\%) children became more pronounced with age, regardless of the Cobb angle. Although previous reports have stated that the lacunar skull became less apparent over time, we observed that the skull persisted over time, often became more obvious, and was still present at the age of 16 years (shown in Fig. 1-4).

At our institution, full spinal MRI was performed more often in patients with early-onset scoliosis (before corrective surgery) to evaluate the possible presence of an underlying osseous or neurological problem. Full spinal MRI was not routinely performed on all patients with idiopathic scoliosis. Therefore, most of the 268 patients did not undergo MRI; 56 underwent full spinal MRI. Two patients (3.6\%) exhibited intraspinal neural axis abnormalities in MRI. One had isolated CMs-I (9-year-old girl), and one had isolated CMs-I (11-year-old girl). The ages at first scoliosis diagnosis were 9 and 8 years, respectively (shown in Fig. 5, 6). No additional neurological problems were found in the medical records of the remaining 266 patients with lacunar skulls. During the 10year period, 19 of the 268 patients with such skulls underwent operative correction of their scoliosis.

\section{Discussion}

The associations between intraspinal neural axis abnormalities and idiopathic scoliosis are well known, but no relationship has been identified between idiopathic scoliosis and the lacunar skull. We found, contrary to 

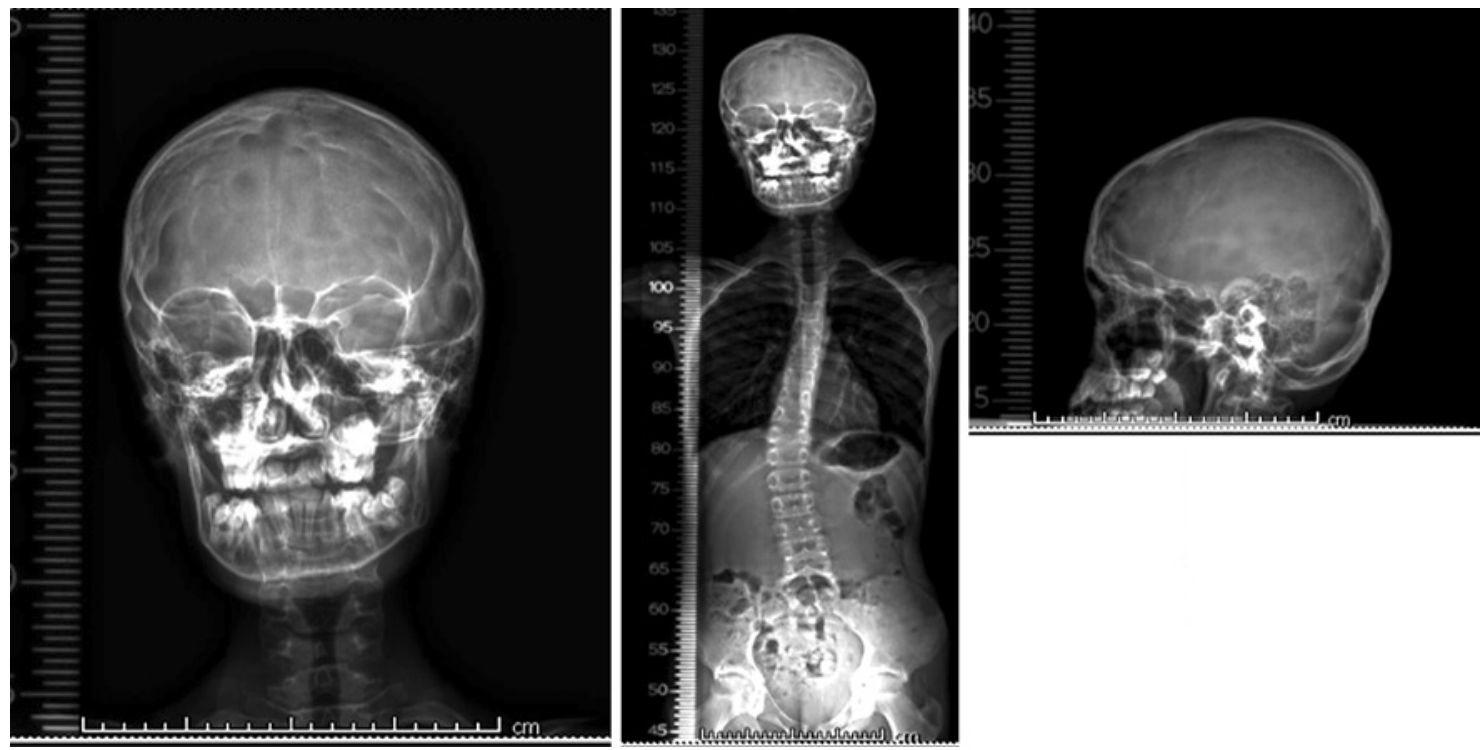

Fig. 2. A 15-year-old adolescent boy with marked lacunar skull (multiple oval, round, and finger-shaped pits on the inner surface of the vault, lie in frontal and parietal bones) and idiopathic scoliosis (right thoraco-lumbar scoliosis, curve of $29^{\circ}$ ) without any additional neurological pathology.
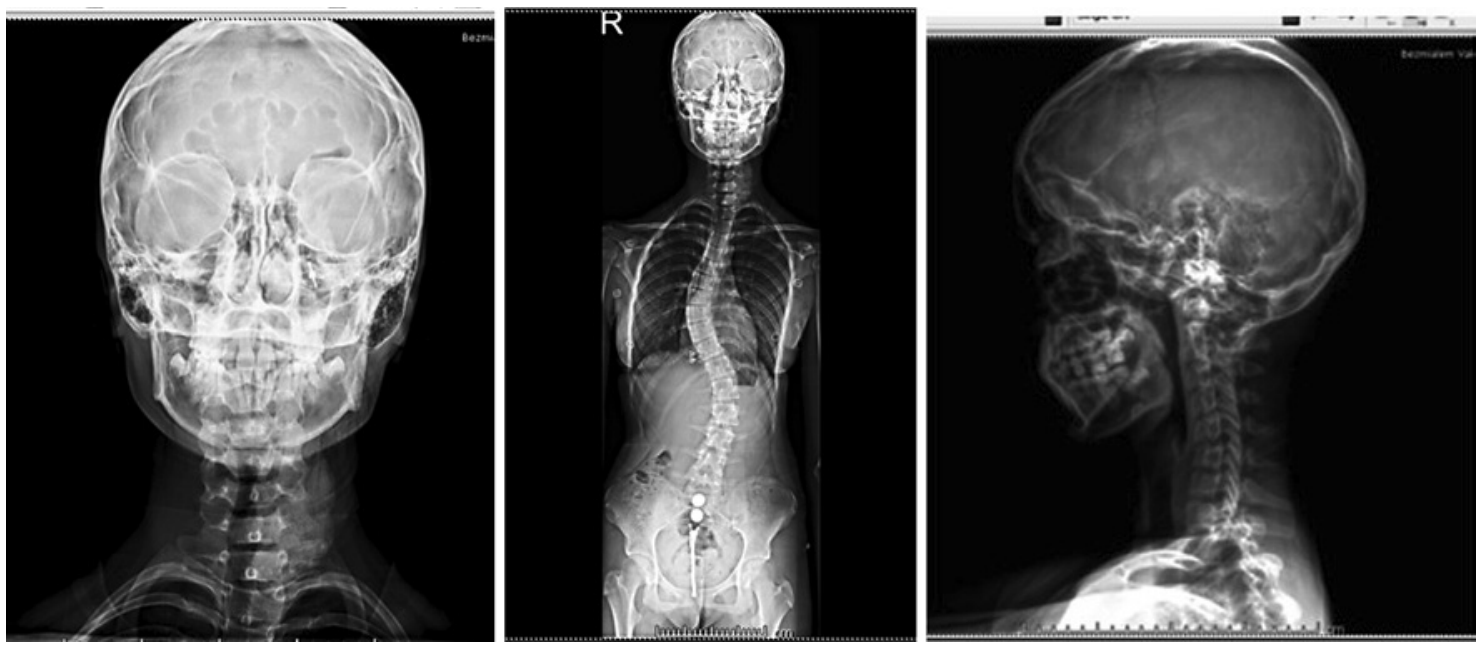

Fig. 3. A 13-year-old adolescent girl with marked lacunar skull and idiopathic scoliosis (right thoracic left lumbar scoliosis: respectively, curve of $45^{\circ}$ and $40^{\circ}$ ).

common belief, that the lacunar skull is a very common benign condition that is not associated with any additional neurological pathology in children with idiopathic scoliosis. Two hundred sixty-eight of 1,760 patients with idiopathic scoliosis exhibited clear lacunar skulls in spinal radiographs; 56 of them underwent full spinal MRI and 2 had isolated Chiari malformation-I. Neither of the 2 patients with a CM-I required surgery.
The term "lacunar skull" refers to a dysplasia of the membranous bone; well-defined radiolucent areas in the calvaria correspond to nonossified fibrous bone. Lacunar skull has been frequently (up to $80 \%$ of cases) associated with CMs I-II and less commonly with encephalocele and craniosynostosis [20-22]. Coley et al. [23] performed neurosonography on 21 patients with myelomeningoceles to explore the possible presence of an irregular inner 

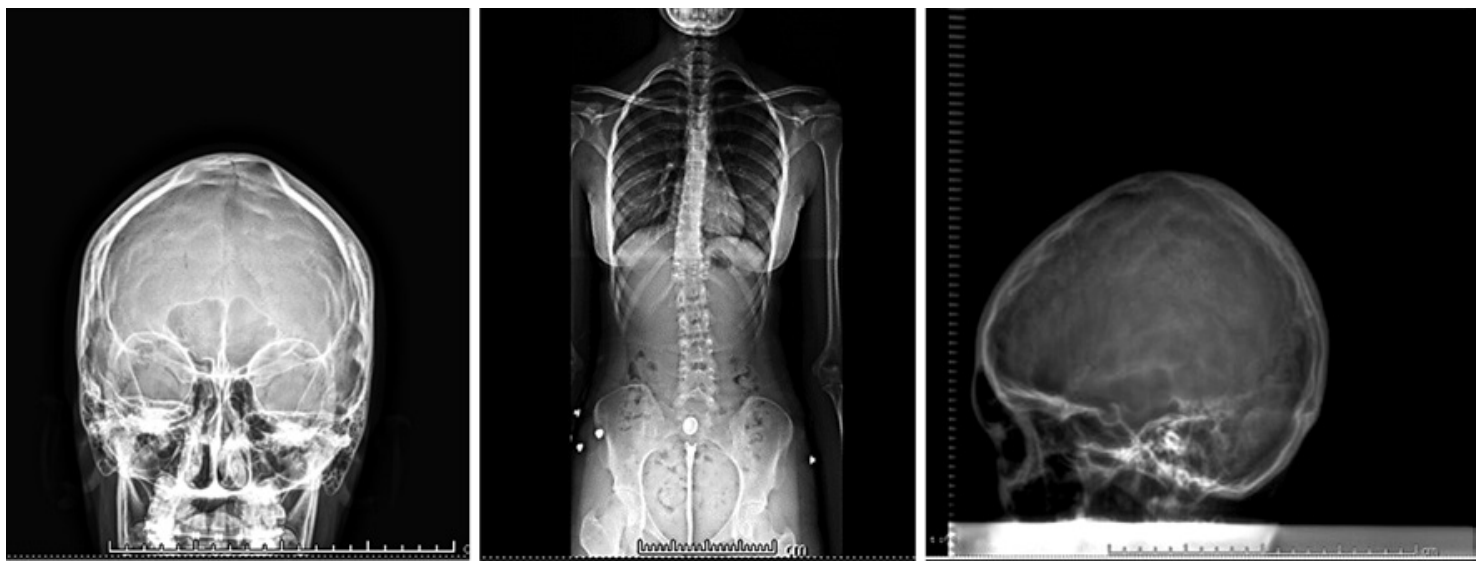

Fig. 4. A 16-year-old adolescent girl with marked lacunar skull and idiopathic scoliosis (right thoracic scoliosis, curve of $20^{\circ}$ ).
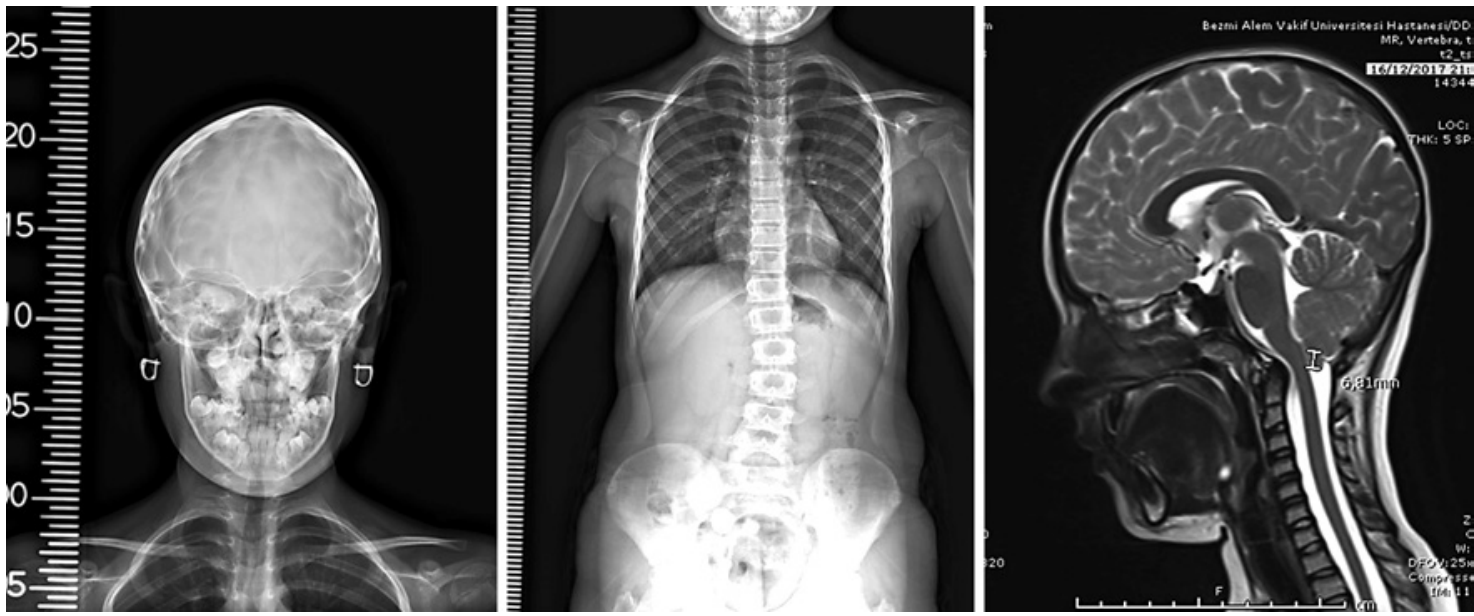

Fig. 5. A 9-year-old girl diagnosed idiopathic scoliosis (left lumbar scoliosis, curve of $22^{\circ}$ ) and lacunar skull. MRI scan demonstrated a CM-I (tonsillar herniation into the foramen magnum, $6.81 \mathrm{~mm}$ ).

calvarial table indicating Luckenschadel skull; 9 patients exhibited prominent Luckenschadel findings, 9 had mild findings, and 3 were normal. The condition was first described by Engstler [3] as the "Luckenschadel" (gap skull) of a 4-day-old infant with spina bifida and has since been considered to reflect a severe neurological disease. To the best of our knowledge, this is the first report to show that lacunar skull is very common in children with idiopathic scoliosis lacking any neurological problem.

This condition has been suggested to be a fetal developmental anomaly caused both by changes in intracranial pressure during pregnancy and developmental anomalies of the calvarium and internal periosteum [24].
A current theory suggests that the CM-II and the Luckenschadel skull reflect the absence of cerebral ventricular distension because of decompression of an open neural tube [25]. Such a lack of stretching inhibits the normal development of membranous plates of the fetal calvarium, creating abnormally irregular collections of collagen fibers that, when ossified, yield the radiographic findings of the Luckenschadel skull. Its dissolution at 6 months of age may reflect remodeling in response to the normal enlargement of cerebral tissue or the development of hydrocephalus [26]. To the best of our knowledge, this theory has not yet been proven, and we believe that it is incorrect. In our study, the lacunar skull was found to persist even 

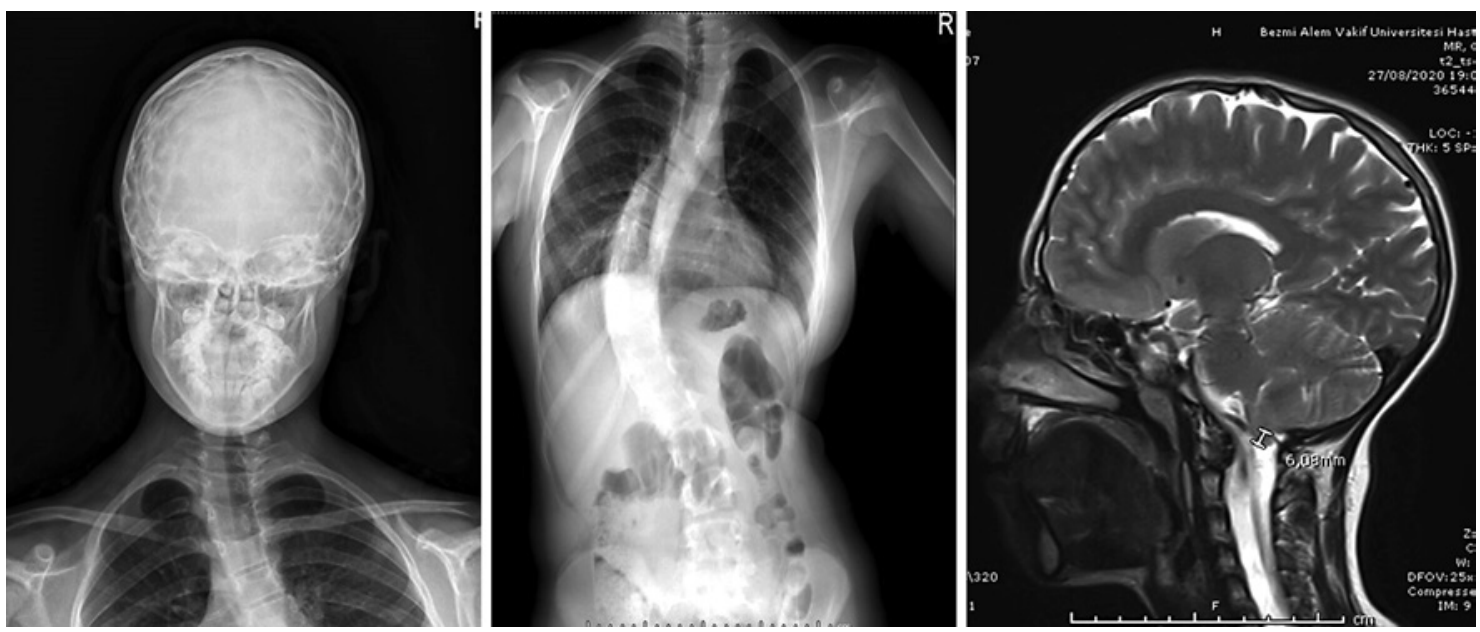

Fig. 6. An 11-year-old girl was diagnosed idiopathic scoliosis (right thoracic scoliosis, curve of $60^{\circ}$ ) and lacunar skull (clearly pronounced finger-shaped pits on the skull). MRI scan demonstrated a CM-I (tonsillar herniation into the foramen magnum, $6.08 \mathrm{~mm}$ ).

in adolescents with idiopathic scoliosis but without any underlying neurological disease. We believe that Luckenschadel skull is not attributable to increased intracranial pressure, but rather to abnormal ossification.

Evidence-based information on the ages of onset and completion of lacunar skull is lacking. All previous studies have reported that lacunar skull is evident at birth and disappears spontaneously within 4-6 months. We report for the first time that it persists to at least the age of 16 years and does not decrease, but rather increases, over time, becoming very pronounced with age in some children. If lacunar skull is attributable to a high intracranial pressure during the intrauterine period, as previously suggested, it is difficult to explain why it is still present (and becomes even more pronounced) in the absence of an increase in intracranial pressure at the age of 16 years. The current lack of better understanding of this condition is due to the lack of radiological data on the incidence of lacunar skull in healthy children.

Several studies have explored the incidences of intraspinal abnormalities in patients with idiopathic scoliosis. A meta-analysis reported a high overall frequency of neuro-axial abnormalities evident in MRI in patients with adolescent idiopathic scoliosis ( $8 \%$ in pooled analyses of $>4,000$ patients) [27]. Pereira et al. [28] reported that the incidence of intraspinal abnormalities was $5.6 \%$ in patients aged $<10$ years. Zhang et al. [29] studied patients $<10$ years of age and found that the prevalence of intraspinal neural axis abnormalities in those with presumed idiopathic scoliosis was $18.7 \%$. Another study reported that this rate was $13.0 \%$ in children with infantile scoliosis [30]. Tully et al. [31] found that $14.7 \%$ of patients under 18 years of age with presumed idiopathic scoliosis but normal neurological examinations evidenced neuro-axial disease in full spinal MRI. Early-onset scoliosis is associated with a higher rate of neurological abnormalities. In the present study, as expected, lacunar skull and additional spinal and cranial anomalies were more common in infantile scoliosis patients $<6$ years of age. Therefore, we did not include these children.

We found that the incidence of neuro-axial abnormalities was $3.6 \%$ in children with lacunar skulls who underwent spinal MRI; 2 of 56 had isolated CMs-I. None required scoliosis surgery, and no increase in intracranial pressure was evident in cranial MRI. In addition, both the patients were neurologically normal. Given the high incidence of lacunar skull, if all patients had undergone spinal MRI, it is likely that stronger associations would have been evident between idiopathic scoliosis, lacunar skull, and CMs.

This study has several limitations. It was retrospective in nature, and we included both children and adolescents. Not all children with scoliosis and lacunar skull underwent full spinal MRI, only $20.9 \%$ of them did. The strengths of the study include the large sample size and the fact that all lacunar head images were saved. The medical files of all children with lacunar skulls were reexamined in terms of neurological disease. We believe 
that this study contributes to the literature on lacunar skull and emphasizes the need to examine the associations among lacunar skull, idiopathic scoliosis, intraspinal anomalies, and the need for MRI. However, there is a clear need for a prospective clinical study in which all children will be evaluated via X-ray, full spinal MRI, and neurologically.

\section{Conclusion}

Lacunar skull does not always indicate the presence of an intraspinal neural axis abnormality; it is a very common benign condition in patients with idiopathic scoliosis without any additional neurological pathology. In addition, it does not disappear over time, and in fact may become more obvious even up to the age of 16 years. Radiological data on the incidence of lacunar skull in healthy children are lacking. More studies are warranted to clarify whether the lacunar skull is a variant of normal skull development.

\section{Acknowledgment}

The author of this manuscript would like to thank Dr. Hazar Dogus who controlled the radiological image.

\section{Statement of Ethics}

The Bezmialem Vakıf University Local Research Ethics Committee approved this retrospective study and waived the requirement for written informed consent.

\section{Conflict of Interest Statement}

The author has indicated that there are no potential conflicts of interest to disclose.

\section{Funding Sources}

The author has indicated that there are no financial relationships relevant to this article to disclose.

\section{Author Contributions}

A.V. designed the study. A.V. collected data and wrote the manuscript.

\section{Data Availability Statement}

We interrogated the database of Bezmialem Vakıf University Hospital (Istanbul).

\section{References}

1 Darouich S. Luckenschadel associated with chiari Type II malformation: an autopsy case report. Fetal Pediatr Pathol. 2020 Feb;25:1-5.

2 Van Leeuwen K. Lacunar skull of the newborn infant. J Pediatr. 1946 Feb;28:193-9.

3 Schtjller A. Roentgen diagnosis of diseases of the head. Malformation of the Skull. St. Louis C. V: Mosby Company; 1918. p. 39-40.

4 Vaesen F, Thimmesch M, Born J, Misson JP. [A rare case of lacunar skull deformity associated with craniosynostosis]. Rev Med Liege. 2016 Mar;71:120-3.

5 Krishnan P, De R, Mishra R, Jena M. A rare case of lacunar skull with craniosynostosis. Neurol India. 2012 Nov-Dec;60:669-70.

6 Vigliani MB. Luckenschadel skull: a forgotten entity. Obstet Gynecol. 2008 Feb;111(2 Pt 2): 562-5.

7 McLone DG, Dias MS. The Chiari II malformation: cause and impact. Childs Nerv Syst. 2003 Aug; 19:540-50.

8 Altaf F, Drinkwater J, Phan K, Cree AK. Systematic review of school scoliosis screening. Spine Deform. 2017 Sep;5:303-9.

9 Weinstein SL, Dolan LA, Cheng JC, Danielsson A, Morcuende JA. Adolescent idiopathic scoliosis. Lancet. 2008;371:1527-37.
10 Fadzan M, Bettany-Saltikov J. Etiological theories of adolescent idiopathic scoliosis: past and present. Open Orthop J. 2017 Dec 29;11: 1466-89.

11 Konieczny MR, Senyurt H, Krauspe R. Epidemiology of adolescent idiopathic scoliosis. J Child Orthop. 2013 Feb; 7:3-9.

12 Chotai S, Basem J, Gannon S, Dewan M, Shannon CN, Wellons JC, et al. Effect of posterior fossa decompression for Chiari Malformation-I on scoliosis. Pediatr Neurosurg. 2018;53:108-15.

13 Dauser RC, DiPietro MA, Venes JL. Symptomatic Chiari I malformation in childhood: a report of 7 cases. Pediatr Neurosci. 1988;14: 184-90.

14 Zhu Z, Yan H, Han X, Jin M, Xie D, Sha S, et al. Radiological features of scoliosis in Chiari I malformation without syringomyelia. Spine. 2016 Mar;41:E276-81.

15 Shen J, Tan H, Chen C, Zhang J, Lin Y, Rong $\mathrm{T}$, et al. Comparison of radiological features and clinical characteristics in scoliosis patients with Chiari I malformation and idiopathic syringomyelia: A matched study. Spine. 2019 Dec 1;44:1653-60.
16 Krieger MD, Falkinstein Y, Tolo VT, McComb JG. Scoliosis and Chiari malformation Type I in children. J Neurosurg Pediatr. 2011 Jan;7:25-9.

17 Noureldine MHA, Shimony N, Jallo GI, Groves ML. Scoliosis in patients with Chiari malformation type I. Childs Nerv Syst. 2019 Oct;35:1853-62.

18 Koc T, Lam KS, Webb JK. Are intraspinal anomalies in early onset idiopathic scoliosis as common as once thought? A two centre United Kingdom study. Eur Spine J. 2013 Jun; 22(6):1250-4.

19 Heemskerk JL, Kruyt MC, Colo D, Castelein RM, Kempen DHR. Prevalence and risk factors for neural axis anomalies in idiopathic scoliosis: a systematic review. Spine J. 2018 Jul; 18:1261-71.

20 Pawar N, Padmavathy S, Maheshwari D, Ravindran M, Ramakrishanan R. OCT-documented optic atrophy in nonsyndromic craniosynostosis and lacunar skull. J AAPOS. 2017 Feb;21:78-81.

21 El Khashab M, Nejat F, Yazdani S, Baradaran $\mathrm{N}$. Acquired craniomeningocele in an infant with craniosynostosis: a case report. J Med Case Rep. 2010 Apr 11;4:104. 
22 Abdelmalik N, Op de Coul ME. [A girl with a lacunar skull]. Ned Tijdschr Geneeskd. 2010; 154:A1595.

23 Coley BD. Ultrasound diagnosis of luckenschadel (lacunar skull). Pediatr Radiol. 2000 Feb;30:82-4.

24 Glass RB, Fernbach SK, Norton KI, Choi PS, Naidich TP. The infant skull: a vault of information. Radiographics. 2004 Mar-Apr;24: 507-22.

25 Hiremath SB, Fitsiori A, Boto J, Torres C, Zakhari N, Dietemann JL, et al. The perplexity surrounding Chiari Malformations - are we any wiser now? AJNR Am J Neuroradiol. 2020 Nov;41(11):1975-81.
26 Hidalgo JA, Tork CA, Varacallo M. Arnold Chiari Malformation. StatPearls; 2021. Available from: https://www.ncbi.nlm.nih.gov/ books/NBK431076/Accessed 2020 May 8

27 Faloon M, Sahai N, Pierce TP, Dunn CJ, Sinha $\mathrm{K}$, Hwang KS, et al. Incidence of neuraxial abnormalities is approximately $8 \%$ among patients with adolescent idiopathic scoliosis: A meta-analysis. Clin Orthop Relat Res. 2018 Jul;476:1506-13.

28 Pereira EAC, Oxenham M, Lam KS. Intraspinal anomalies in early-onset idiopathic scoliosis. Bone Joint J. 2017 Jun;99-B:829-33.
29 Zhang W, Sha S, Xu L, Liu Z, Qiu Y, Zhu Z. The prevalence of intraspinal anomalies in infantile and juvenile patients with "presumed idiopathic" scoliosis: a MRI-based analysis of 504 patients. BMC Musculoskelet Disord. 2016 Apr 27;17:189.

30 Pahys JM, Samdani AF, Betz RR. Intraspinal anomalies in infantile idiopathic scoliosis: prevalence and role of magnetic resonance imaging. Spine. 2009 May 20;34:E434-8.

31 Tully PA, Edwards BA, Mograby O, Davis HSM, Arieskola O, Magdum S, et al. Should all paediatric patients with presumed idiopathic scoliosis undergo MRI screening for neuro-axial disease? Childs Nerv Syst. 2018 Nov;34:2173-8. 